\title{
Runway performance following changes in sucrose rewards'
}

\author{
Alexander J. Rosen and James R. Ison \\ UNIVERSITY OF ROCHESTER
}

\begin{abstract}
Abstraet
Three groups of rats $(\mathrm{N}=21)$ received 43 runway trials for 400 licks of a $20 \%$ solution, 400 licks of a $3 \%$ solution, or 20 licks of a $3 \%$ solution (Stage 1), all followed by 36 trials at 20 licks, $3 \%$ (Stage 2). Stage 1 response speeds were determined by both concentration and number of licks. Speeds in Stage 2 changed less rapidly than has been observed in previous studies; the group shifted in both number and concentration remained above the control level for the duration of the experiment.

\section{Problem}

It has become increasingly apparent that the rapidity of the performance change in instrumental conditioning contingent on a shift in reward value is critically determined by the type of reward manipulated. Studies using solid food rewards typically obtain one or two trial performance shifts (i.e., Crespi, 1942) whereas shifts in sucrose concentrations produce comparatively slow changes (Homzie \& Ross, 1962). The present study is part of a series designed to evaluate the effects of changes in concentration and consummatory behavior with sucrose rewards.
\end{abstract}

\section{Method}

Twenty-one male albino rats, 120 days old, were placed on a $23 \mathrm{hr}$. food deprivation schedule and assigned randomly to one of three groups differing in the reward magnitude obtained in the preshift trials: 400 licks at
20\%; 400 licks at 3\%; 20 licks at 3\%. Forty-three preshift trials were followed by 36 postshift trials at 20 licks, $3 \%$. Trials were run at six per day except that the first six trials were run at two per day, and the first postshift day began with the last preshift reward trial. Trials began each day at approximately a $21 \mathrm{hr}$. deprivation time.

The runway consisted of a 12 in startbox, a 56 in alleyway and a 15-1/2 in goalbox, all 4 in wide. Photocells, placed on the startdoor and 6 in, 55 in and 64 in from the startdoor, in conjunction with Hunter silent relays and clocks, recorded start, running and goal times. (Only total running speed, the reciprocal of the aggregate times, will be reported here.) Adrinkometer circuit (Mason, 1964), housed in a sound attenuating box, controlled the number of licks on one of two drinking tubes and, in conjunction with a fourth Hunter clock, permitted the measurement of total drinking time. Each tube administered a different concentration and could be placed $1 / 8$ in from a $1 / 2$ in hole in the side of the alley, to be pulled away by a solenoid in circuit with the drinkometer. Ss were removed from the goalbox within 1-2 sec. of reward offset.

\section{Results}

Stage 1: Mean running speed for each trial is depicted in Fig. 1. It is clear the running speed was greater with increases in both concentration and amount

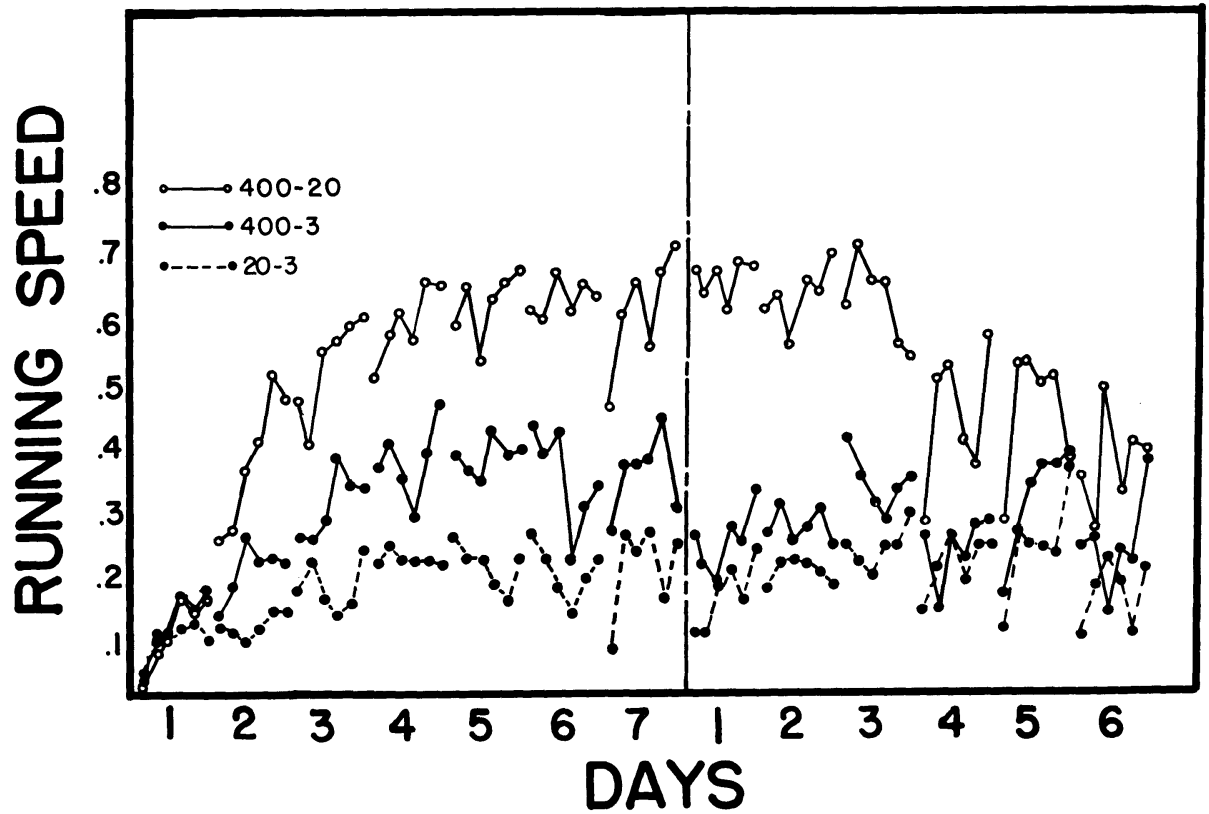

Fig. 1. Total running speed (1/time) for 42 preshift trials of groups receiving 400 licks of a $20 \%$ solution, 400 licks of a $3 \%$ solution and 20 licks of a $3 \%$ solution, and the 36 postshift trials, all at 20 licks, $3 \%$ 
of consummatory behavior. A two-way mixed analysis performed on the subject day means in Stage 1 yielded a Groups effect, a Trials effect and a G x T interaction, all beyond the .001 level. Two additional analyses of variance indicated that Group 400-20\% was faster than Group $400-3 \%(p<.005)$ which in turn was faster than Group $20-3 \%(p<.05)$ 。 Licking rate was related to concentration; a two-way analysis of licks/sec. yielded the Groups, Trials, and G x T interaction at beyond the .001 level. The separate analyses indicated that although Group 400-20\% was faster than Group 400-3\% ( $<<.001)$, the latter group was not significantly different from Group $20-3 \%(F(1,12)=2.90 ; p>.10)$. The total correlation between licking and running speed was +.38 ; within group correlations were $+.40,+.31$ and +.25 for Groups $400-20 \%, 400-3 \%$ and $20-3 \%$, respectively.

Stage 2: In Fig. 1 it is apparent that the preshift differences in performance were not entirely eliminated in the postshift trials. A mixed design analysis of variance again yielded the Groups, Trials and $\mathrm{G} \times \mathrm{T}$ interaction significant at beyond the .001 level. The interaction clearly resulted because Group 400-20\% declined in the postshift days whereas the other groups did not. However, a t-test performed on the subject means of the last postshift day indicated that Groups $400-20 \%$ and $20-3 \%$ were still disparate $(t(12)=2.05 ; p<.05,1$-tail $)$. A separate analysis of variance performed on Groups 400-3\% and $20-3 \%$ indicated that these groups were not different in Stage $2(p>.20)$. The preshift differences in licking rate were maintained in Stage 2: Group 400-20\% licked faster than Group 400-3\% ( $p<.01)$, which did not differ from Group $20-3 \%(p>.20)$. No decrement in licking rate occurred in the postshift trials and, consistent with the small nonsignificant difference favoring Group 400-3\% over Group 20-3\% on running speeds, there was a small insignificant difference favoring their drinking speeds. The total correlation between licking rate and running speeds in Stage 2 was +.32 ; within group correlations were $+.15,+.18$ and +.22 for Groups $400-20 \%, 400-3 \%$ and $20-3 \%$. It should be noted that consummatory behavior was continuous in Stage 2, and Ss did not take time out from drinking.

\section{Diseussion}

Most striking in the present data is the slow change in performance demonstrated by Group 400-20\%, the group shifted down in both number of licks and concentration of sucrose. This should be contrasted with the 1 or 2 trial change with food rewards, and with the 20 trial change observed by Homzie \& Ross (1962) in a group switched from $.1 \mathrm{ml}$ of a $20 \%$ solution to $.1 \mathrm{ml}$ of a $1 \%$ solution. These workers suggested that their result might have been obtained because their manipula- tion of reward did not change the duration and amount of consummatory behavior, which food rewards necessarily change. However, in the present study these were changed by a factor of $20: 1$, and thus the explanation of Homzie and Ross does not seem appropriate for the slow changes observed with sucrose rewards.

It is possible that the locus of the effect is the preshift difference in concentration, and thus it might be assumed that different concentrations of sucrose determine different values of some permanent excitatory construct, i. e., habit. It is to be remarked, parenthetically, that these shifts in concentrations are completely in accord with Hull's early predictions on the effects of decrements in reward magnitude (1943, p.131), and it is interesting to speculate about the later historical development of $\mathrm{K}$, the incentive motivational construct, if Crespi had used sucrose concentrations instead of units of dog chow. This suggests that shifts of number of licks within a concentration are equivalent to shifts in food rewards, and assumes that the small insignificant postshift difference between Groups $400-3 \%$ and $20-3 \%$ is in fact a zero difference. We are not yet prepared to make this assumption.

It is also possible that the differences in postshift performance remain because the postshift rewards maintained the preshift differences in licking rate (not duration or number of licks). This is appealing for those theories which place heavy emphasis on the response elicitation properties of reinforcement (e.g., Sheffield, Roby \& Campbell, 1954; Premack, 1959; Spence, 1956), but the correlations between licking rate and running speed, though of the moderate magnitude characteristic of these situations, do not account for a great percentage of the variance between Ss.

\section{References}

CRESPI, L. P. Quantitative variation of incentive and performance in the white rat. Amer. J. Psychol., 1942, 55, 467-517.

HOMZIE, M. J., \& ROSS, L. E. Runway performance following a reduction in the concentration of a liquid reward. J. comp. physiol. Psychol., 1962, 55, 1029-1033.

HULL, C. L. Principles of behavior. New York: Appleton-CenturyCrofts, 1943.

MASON, D. J. An apparatus and method for rigorously controlling amount of reward and amount of consummatory activity. Psychol. Rep., 1964, 14, 388-390.

PREMACK, D. Toward empirical behavior laws: I. Positive reinforcement. Psychol. Rev, , 1959, 66, 219-233.

SHEFFIELD, F。D., ROBY, T. B., \& CAMPBELL, B. A. Drive reduction versus consummatory behavior as determinants of reinforcement. J. comp. physiol. Psychol., 1954, 47, 349-354.

SPENCE, K. W. Behavior theory and conditioning. New Haven: Yale University Press, 1956.

Note

1. This research was supported by research grant NSF GB1505 to

J. R. Ison. Computer time for data reduction and analysis was supported in part by The College of Arts and Science, University of Rochester. 